Josemir Camilo de Melo

PhD em História, Professor Adjunto do Departamento de História e Geografia, Universidade Federal da Paraíba, Campus II, ex-Coordenador de UNCAL (Unidade de Estudos e Pesquisas sobre Calamidades/UFPB) Campina Grande, PB, Brasil.

E-mail: jcamilo@cgnet.com.br.

\title{
O fenômeno El Niño \\ e as secas no Nordeste do Brasil
}

\section{RESUMO}

Este artigo tenta reconstruir a série de ocorrências de seca no semi-árido brasileiro, associando-a a El Niño. A abordagem é interdisciplinar e tenta verificar a correlação existente entre fenômenos naturais e a ocorrência de desastres. Para isto, se utiliza aqui do aparato teórico da escola de La Red de Estudios Sociales en Prevención de Desastres, sediada em Lima, Peru, para verificar o grau de vulnerabilidade das populações da região, resgatando-se o momento histórico das secas para o devido paralelo. Abordam-se também as diversas políticas públicas implantadas e seus efeitos, questionando-se a manutenção do status quo de vulnerabilidade ainda ocorrente no semi-árido.

Palavras-chaves: El niño, secas, vulnerabilidade.

\section{ABSTRACT}

This article deals with occurrences of droughts in Brazil semiarid region, associated with the El Niño phenomenon. The approach is interdisciplinary and attempts to contest some theories about the occurrence of droughts, as well as to verify the correlation between other natural phenomenon and the occurrence of disaster. For such purpose, it is used the theoretical approach coming from La Red de Estudios Sociales en Prevención de Desastres, headquartered in Lima, Peru, to verify the degree of vulnerability which threaten the region's population, taking into consideration the historical moment of the drought for the proper comparison. Also approached are the various public policies implemented and their effects, raising questions on the maintenance of the status quo of vulnerability still existent in the semi-arid. Key words: El niño, drought, vulnerability.

\section{Introdução}

A área do semi-árido brasileiro mede cerca de $788.064 \mathrm{~km}^{2}$, o que corresponde a $48 \%$ da região Nordeste e 9,3\% do país, segundo um novo redimensionamento proposto pela FUNCEME (Fundação
Cearense de Meteorologia) ${ }^{1}$. Desde as primeiras décadas do século XVI, há registros de secas. A concepção de secas como fenômeno natural inevitável tem gerado um discurso unificado de vitimização, o que tem sido aproveitado pelas elites para seu fortalecimento po- lítico, social e para a reinversão de capital através de políticas públicas paliativas, como frente de trabalho e demais congêneres. No entanto, de acordo com o avanço da tecnologia, sabe-se que a ocorrência de secas está ligada a fenômenos como o El Niño e o Dipolo do Atlântico (aquecimento/ esfriamento do Atlântico Norte/ Sul) e até ao surgimento de atividades vulcânicas (ver adiante a teoria de Luiz Carlos Baldicero Molion).

A ocorrência de secas é secular, porém sua observação como risco e ameaças se dá a partir do grau de concentração de povos brancos no interior da região Nordeste, com sua vida sedentária (ao contrário do nomadismo indígena), ligada à atividade agrícola e pecuária. Os índios também sofriam com as secas, o que prova exatamente seu nomadismo. No caso dos colonialistas, foi a tomada das terras indígenas e sua fixação nelas, com a propriedade privada, que fez sur-
Raizes,

Ano XVIII, $N^{\circ} 20$, novembro/ 99 pp. $13-21$ $\ldots \ldots \ldots \ldots$

- ${ }^{1}$ Segundo o Programa de Estudos e Ações para o Semi-árido, PEASA, da Universidade Federal da

- Paraíba, o semi-árido teria $882.081 \mathrm{~km}^{2}$, ou seja $53,1 \%$ do Nordeste. Ver bibliografia. 
gir e aumentar sua própria vulnerabilidade ao fenômeno das secas ${ }^{2}$.

Segundo informações históricas e técnicas, os dois últimos séculos parecem ter tido o maior número de secas e também as piores. Não obstante, não é pela repetição das secas que a vulnerabilidade tem ocorrido e sim pelo crescimento da população que se estabelece no interior da região, que termina por expor a população ao fenômeno, até então natural, da seca, aumentando os riscos de desastres. Em geral, devido às ocorrências de seca, a região Nordeste já perdeu um século completo de sua produção agro-pastoril, desde o inicio da colonização até nossos dias (ver Tabela 01).

\section{Secas, El Niño e vulcanismo}

Tentamos trabalhar, aqui, com duas vertentes de discussão: o conceito de desastres atribuído às secas e o motor destes fenômenos, segundo as ciências atmosféricas, para verificar a relação entre secas, El Niño e vulcanismo. Ao mesmo tempo, fazemos um inventário das secas ocorridas na região em séculos passados a fim de contribuir para o rastreamento do El Niño.

El Niño é um fenômeno meteorológico de escala global, resultante do aquecimento diferenciado do Oceano Pacífico, provocando alterações no regime de precipitações atmosféricas em várias partes da ter-

Tabela 01

Ocorrência de Secas no Nordeste

\begin{tabular}{|l|c|c|c|}
\hline \multicolumn{1}{r|}{ Período } & Secas & Anos de Seca & Ano p/Seca \\
\hline Século XVI & 5 & 8 & 0.6 \\
\hline Século XVII & 7 & 8 & 0.8 \\
\hline Século XVIII & 15 & 27 & 5.5 \\
\hline Século XIX & $15^{\star}$ & 29 & 5.1 \\
\hline Século XX & $12^{* *}$ & 28 & 4.2 \\
\hline Total & 54 & 100 & 21.2 \\
\hline
\end{tabular}

$\left.{ }^{*}\right)$ Houve 11 repiquetes (invernos falhos) no século XIX que somados aos 29 anos secos corresponderiam a 40 anos de prejuízo agrícola no Nordeste; numa média por ano de 3,6 anos/seca; no cômputo geral, até o fim do século XIX tivemos cerca de 42 secas em 87 anos, ou seja 2 anos por seca;

${ }^{* *}$ Segundo dados de Oribe Aragão, coletados em 67 estações. Os anos de seca foram computados como anos secos, anteriores o posteriores aos anos de seca. A média de anos por seca chega a 3,5 anos.

ra. No Brasil, ocorre uma redução de chuvas nas regiões Norte e Nordeste, e um aumento na região Sul, como a grande seca no Nordeste e as inundações em Santa Catarina, em 1983. Em geral, o El Niño, embora fraco, em 1992-93 afetou a vida de 8 milhões e 500 mil pessoas, numa área de 800 mil quilômetros quadra$\operatorname{dos}^{3}$.

Alguns detalhes que formam o evento El Niño já haviam sido estudados desde a década de 1920, mas foi no final da década de 1960 que Jacob Bjerknes, da Universidade de Califórnia, observou uma conexão entre temperaturas quentes na superfície do mar, os fracos ventos de leste para oeste e as condições de alta precipitação. A teoria de Bjerknes associada aos estudos de Walker eram partes do mesmo fenômeno, conhecido pelo nome de ENOS (El Niño - Oscilação Sul) ${ }^{4}$.

Assim, este fenômeno de aquecimento das águas do Pacífico, termina por impedir que a chuva caia sobre o Nordeste. No entanto, não basta surgir El Niño para que haja secas, como tem demonstrado Dr. Oribe Aragão ${ }^{5}$ (ver Tabela 02). Ele associa ao El Niño o fenômeno, historicamente pouco estudado, do Dipolo do Atlântico, tese do Dr. Divino Moura. Este evento também influencia o grau de seca no Nordeste, ou traz mitigação ao impacto do

\footnotetext{
$\ldots \ldots \ldots \ldots \ldots \ldots$

- ${ }^{2}$ Sobre o conceito de vulnerabilidade, ver WILCHES-CHAUX (1993:1-50).

- ${ }^{3}$ Segundo a Comissão Especial, criada através do Requerimento No 533 de 1997, para gestionar, junto aos órgãos das três esferas de Governo, medidas preventivas em relação às regiões sujeitas ao fenômeno atmosférico "El Niño".

${ }^{4}$ Idem, ibidem

- Idem, ibidem.

- ${ }^{5}$ Dados apresentados no "Seminário sobre A Influência do El Niño na Agricultura e nos Recursos Hídricos do Semi-árido”. Prefeitura Municipal de Campina Grande, 12 e 13 de março de 1998.
} 
El Niño. Outro fenômeno que deve ser abordado é o oposto do El Niño: La Niña, que corresponde ao esfriamento do Pacífico, como o que ocorreu, por exemplo, em 1988/9, e que chamaria em seu rastro o $\mathrm{El}$ Niño de 1991/2/3, o maior do século. El Niño mais forte, antes, havia sido o de 1982/3, quando houve, na região, seca de 1979 a 83 .

Uma hipótese polêmica, defendida por Dr. Luiz Carlos Baldicero Molion, busca as causas das secas no vulcanismo e, para isso, tem tentado cruzar dados de secas com os de vulcanismo para verificar a influência destes sobre a ocorrência das secas. Molion defende que até o El Niño seria conseqüência do vulcanismo e, para isso, dá, como exemplo, o ano de 1882, em que houve grandes erupções e ocorreu o El Niño. No entanto, para os historiadores, dois fatos necessitam de mais investigações: um é que, em 1882, não houve seca na região Nordeste, e sim em 1888; outro é que a série levantada por Molion mostra um período de descenso do vulcanismo (1912-1945), quando, no entanto, tivemos três grandes secas: 1915 , 1918/9, 1932, além de ter havido um El Niño forte em 1944, seguido de seca $^{6}$.

Aparte a discussão entre os pesquisadores de desastres sobre se as secas são ou não um desastre, visto que já se tornaram um fenômeno previsível, aplicaremos os conceitos de risco, ameaça, vulnerabilidade e desastres de La Red de Estudios Sociales em Prevención de Desastres en América Latina (com sede em
Lima, Peru), já que estes conceitos têm também um sentido político que passa pelo crivo do desenvolvimento, para verificar que o fenômeno das secas tem sido maquiado em sua extensão natural. $\mathrm{O}$ conceito tradicional de vulnerabilidade tende a se reduzir aos efeitos físicos das comunidades afetadas. Um exemplo de riscos contornados, na região, no que se evita a vulnerabilidade, está na tática dos latifundiários de remover o gado para fazendas situadas em serras, brejos úmidos de altitude e zonas litorâneas. Outro detalhe desta desigual vulnerabilidade está no fato de que os grandes proprietários jamais emigram, nem se desfazem de suas propriedades, além de serem os proprietários dos mananciais, não permitindo uma democratização dos recursos hídricos, embora curtos, em tempos de seca.

Dentre os riscos que a população tem provocado, aumentando sua própria vulnerabilidade, está a pecuária extensiva e a agricultura inadequada ao semi-árido, além de uma falta de desenvolvimento das forças produtivas na zona semi-árida, o que

Tabela 02

Ocorrências de El Niño no Nordeste do Brasil

\begin{tabular}{|c|l|c|l|}
\hline Ano & \multicolumn{1}{|c|}{ Fenômeno } & Ano & \multicolumn{1}{|c|}{ Fenômeno } \\
\hline 1914 & El Niño moderado & 1952 & ano seco \\
\hline 1914 & ano seco & $1953 / 4$ & El Niño moderado sem seca \\
\hline 1915 & Seca & 1957 & El Niño forte \\
\hline $1917 / 9$ & El Niño fraco & 1958 & Seca \\
\hline 1918 & El Niño forte e ano seco & 1965 & El Niño moderado \\
\hline 1919 & Seca & 1969 & El Niño fraco \\
\hline 1923 & El Niño fraco & 1972 & El Niño moderado \\
\hline 1925 & El Niño forte sem seca & 1976 & El Niño fraco \\
\hline 1928 & ano seco & 1979 & El Niño fraco e seca \\
\hline 1929 & El Niño moderado & 1980 & ano seco \\
\hline 1930 & ano seco & $1982 / 3$ & El Niño mais forte e seca \\
\hline 1931 & ano seco & 1986 & El Niño fraco \\
\hline 1932 & El Niño fraco e seca & 1987 & El Niño moderado \\
\hline 1941 & El Niño forte e ano seco & 1991 & El Niño moderado \\
\hline 1942 & ano seco & 1992 & El Niño fraco e ano seco \\
\hline 1943 & El Niño fraco e ano seco & $1993 / 4$ & Seca \\
\hline 1944 & Seca & 1997 & El Niño forte \\
\hline 1951 & El Niño fraco e ano seco & 1998 & ano seco (?) (seca) \\
\hline
\end{tabular}

Dados anotados da conferência de Oribe Aragão "O Que é El Niño?" Seminário sobre a Influência do El Niño na Agricultura e nos Recursos Hídricos do Semi-árido, realizado em Campina Grande, Paraíba, 12 e 13 de março de 1998.

- ${ }^{6}$ Idem, ibidem. 
tem levado a população ao desmatamento para uso de energia (carvão e lenha) e utilidades (móveis, cercas, construções) originando, então, zonas de desertificação.

As políticas públicas têm privilegiado a mitigação dos efeitos da seca, porém não tem sido uma política de eliminar os riscos, para evitar as ameaças e, assim, diminuir o grau de vulnerabilidade das comunidades do semi-árido. A indecisão no uso do conceito de vulnerabilidade nas políticas públicas e da concepção tradicional de desastres têm levado o governo federal, por exemplo, a incluir o estado do Maranhão (com predominância de matas) dentro das políticas públicas de mitigação às secas, quando, em 1981-82, teve situação de emergência declarada em metade de seus 131 municípios.

Assim, o discurso nivelador das elites regionais tem atribuído ao fenômeno El Niño uma série de desastres ocorridos entre 1982/3 e 1997/ 8, o que tem levado vários especialistas a estudar o comportamento da população frente aos riscos, ameaças e desastres ocorridos anteriormente com outros aparecimentos de El Niño.

Tem sido, realmente, o El Niño o responsável por toda a série de secas ocorrida no Nordeste desde o período colonial? Este não é o ponto de vista de Dr. Oribe (ARAGÃO, 1998) que rastreou o El Niño e as secas desde 1914, tomando como base uma série de ciclos de 13 anos. Para tanto, no decorrer de 83 anos observados, o autor verificou que só houve 3 anos chuvosos no Nordeste, (1917, 1929 e 1984). Considerou ele, ainda, o que chamou de anos normais a 11 anos: 1916, 1945, 1956, 1957, 1969, 1971, 1973, 1981, 1994, 1995 e 1996. Somados os anos normais aos chuvosos, teríamos só 14 anos sem seca, entre aqueles 83 , ou seja, algo ao redor de $16,8 \%$ de anos produti$\operatorname{vos}^{7}$.

Não obstante, Oribe só relata 28 anos secos, entre 1914 e 1997, relacionados com o El Niño e nem todos de intensidade forte. Em sua investigação, Oribe aponta só $6 \mathrm{El}$ Niño fortes, 7 moderados e 10 fracos. Parece querer dizer que El Niño nem sempre é sinônimo de seca e, mesmo quando esta ocorre em algumas microrregiões do semi-árido, os efeitos do El Niño nem sempre significam a mesma ameaça. Tomando, por exemplo, a seca de 1932, originada por um El Niño fraco, naquele mesmo ano, esta seca gerou no Ceará uma situação de calamidade pública devido à qual foram postas em prática políticas de isolamento das populações afetadas com a manutenção de verdadeiros campos de concentração ${ }^{8}$.

Desde 1914, período base da medição de Oribe, através de 67 estações coletoras, que a ocorrência do El Niño, seja em qualquer intensi- dade, não tem sido diretamente tão responsável peia ocorrência de secas. Isso a começar pelo ano de 1914, quando o El Niño foi moderado, e a seca grande, prolongando-se no ano seguinte. Em 1918, ocorreu um El Niño forte, mas a seca só apareceu um ano depois. Durante a década de 1920 só houve um El Niño moderado e nenhum registro de grande seca, embora tenha havido um ano (1928) seco. Na década de 1930, ocorreu só o El Niño de 1932 e sua conseqüente seca naquele mesmo ano 9 .

Parece que quando ocorre um El Niño forte, a seca surge no ano seguinte, como aconteceu em 1918 e voltou a ocorrer em 1941. Este ano foi seco e a situação se agravou nos dois anos seguintes, continuando, ainda, a seca em 1944, mas, neste ano, alimentado por um El Niño fraco, o de 1943. A década de 1950, de acordo com os dados levantados por Oribe, apresenta uma situação típica, em que a ocorrência de El Niño, em 1957, resultou em aquele ano ser seco, porém desencadeou, no ano seguinte, uma das maiores secas na região. Esta década foi a que mais registrou situações de seca neste século: 6 anos secos quase que em seguida, de 1951 a 1955 (sendo 2 de verdadeira seca) além da de 1958 e dois anos normais, sem nenhum ano chuvoso $^{10}$.

A década de 1960 não conheceu seca, embora o El Niño tenha ocor-

\footnotetext{
- ${ }^{7}$ Idem, ibidem.

- 8 "Campos de concentração, a face mais cruel da seca". O Globo, 22 de março de 1998, p.16.

- ${ }^{9}$ Aragão, Oribe. op. cit.

- ${ }^{10}$ Idem, ibidem.
} 
rido duas vezes: em 1965, moderado e, em 1969, fraco; não obstante, este último resultou na seca de 1970 . Na década de 1970, o El Niño voltaria a ocorrer três vezes. Em 1972, surgiu moderado, com ano seco; em 1976, fraco, com ano seco; porém, em 1979, surgiu com este ano e o seguinte secos, seguidos ainda de 1982, com El Niño forte, prosseguindo até 1983, quando a seca evoluiu, só sendo interrompida pelo ano chuvoso de 1984. A década de 1980 ainda veria mais um El Niño fraco, em 1986, coincidindo com um ano chuvoso, em 1987, e um El Niño moderado, sem ano seco. Em 1991, o El Niño surge moderado e, no ano seguinte, fraco, mas gerando um ano seco, seguido de seca - a de 1993. Novamente o fenômeno atinge o Nordeste em 1997/8, com uma das maiores secas do século.

\section{El Niño e as consequiências sociais no Nordeste do Brasil}

Embora a seca pareça ser genérica no Nordeste do Brasil, não o é, quanto à zona da mata. Por exem-

Tabela 03

Cronologia de Secas no Século XIX

\begin{tabular}{|c|l|}
\hline $1803 / 4$ & Paraíba \\
\hline 1809 & Sem lugar determinado \\
\hline $1816 / 7$ & Paraíba \\
\hline $1824 / 5$ & Ceará, Paraíba e Pernambuco \\
\hline $1826 / 7$ & Secas parciais \\
\hline 1830 & Falta de chuvas na Paraíba \\
\hline $1835 / 7$ & Sem indicação de lugar \\
\hline $1844 / 6$ & Paraíba e Pernambuco \\
\hline 1851 & "Repiquete" (inverno falho) \\
\hline 1853 & Idem \\
\hline 1860 & Idem \\
\hline $1865 / 66$ & Idem \\
\hline $1867 / 70$ & Seca principalmente no Ceará \\
\hline $1869 / 70$ & Repiquete \\
\hline 1870 e 1872 & Alagoas, Pernambuco e Paraíba \\
\hline $1877 / 79$ & Seca: todo o Nordeste \\
\hline $1888 / 9$ & Seca, principalmente no Ceará \\
\hline 1889 & "Repiquete" \\
\hline $1891 / 2$ & Idem \\
\hline 1895 & Seca \\
\hline 1896 & Repiquetes \\
\hline 1898 & Seca, regional \\
\hline 1889 & Seca em Rio Grande do Norte e Paraíba \\
\hline & \\
\hline
\end{tabular}

- ${ }^{11}$ Almanaque Abril. São Paulo: Abril Editora, (exemplares anuais de 1991 a 1995)

- ${ }^{12}$ Idem, ibidem.

plo, quando em junho de 1990 havia seca no semi-árido, chuvas torrenciais se abatiam sobre Recife, durante 15 horas, deixando 18 mortos e 2.000 desabrigados. Foram 10 dias de chuvas fortes em Recife, matando 31 pessoas e deixando 23.000 desabrigados e 27 casos de leptospirose ${ }^{11}$. Mesmo cidades relativamente distantes do litoral, como Campina Grande, no Planalto da Borborema, nos limites do semiárido paraibano, zona de convergência de correntes atmosféricas, teve, em 1993, um inverno com bastante chuva, que inundou casas e ruas, com prejuízos de 1 milhão de dólares. Isto também mostra a desigual vulnerabilidade que se abate sobre a região, com zonas do litoral sob chuvas e 200 quilômetros, a oeste, a seca.

Desde 1990, antes mesmo de a ciência mostrar que El Niño chegaria um ano mais tarde, a seca já fazia estragos. Trezentos camponeses, "flagelados" pela seca, saqueavam uma escola no Piauí, ao mesmo tempo em que 250 outros atacavam um armazém público em Pernambuco e, no Ceará, outros camponeses invadiam um depósito de gêneros, além de cometerem vários outros saques $^{12}$.

O El Niño, embora moderado e fraco entre 1991 e 1993, terminou em uma seca, em 1993, que se prolongou em 1994. No entanto, em 1992, a SUDENE anunciava que a seca atingia 800 municípios (numa área de $869.000 \mathrm{~km}^{2}$ ) e que grande parte da agricultura já estava perdida. Isto

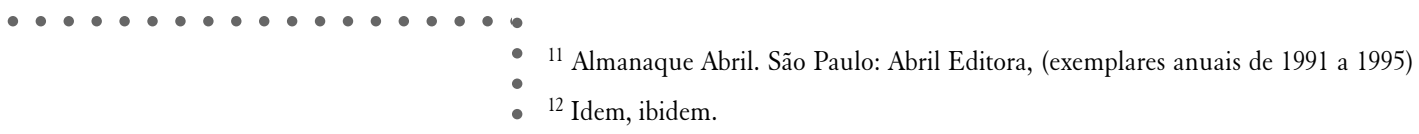


Tabela 04

Vítimas da Seca de 1877/9 (em milhares)

\begin{tabular}{|l|c|c|}
\hline \multicolumn{1}{|c|}{ Província } & População Estimada & População Afetada \\
\hline Piauí & 202 & - \\
\hline Ceará & 800 & 720 \\
\hline Rio Grande do Norte & 234 & 117 \\
\hline Paraíba & 362 & $60^{*}$ \\
\hline Pernambuco & 841 & 200 \\
\hline Alagoas & 348 & 50 \\
\hline Sergipe & 161 & 30 \\
\hline Bahia & 1.283 & 500 \\
\hline TOTAL & 4.231 & 1.667 \\
\hline
\end{tabular}

Fonte: Dados abreviados de Reboucas, André. A Seca nas Províncias do Norte. Socorros Públicos. Rio de Janeiro, 1877, pp. 32/4. Os dados são estimativas daquele autor;

(*) os dados para Paraiba são do Cônsul inglês Walker. British Parliamentary Paper, LXXV, 1878. Report be Consul Walker on the Famine in the Northern Provinces of Brazil. London, 1878.

gerou fome e, no ano seguinte, o governo enviou 110 toneladas de feijão para Pernambuco; a Paraíba receberia, por sua vez, 270 toneladas de alimentos para mitigar a fome. Novamente, se voltava aos métodos paliativos, constituindo-se frentes de trabalho, cujo custo chegava a mais de 7,2 bilhões de cruzeiros para o programa de mitigação que incluía a doação de 1 milhão de cestas básicas ${ }^{13}$.

Esta crise levou a Universidade de São Paulo, baseada em estudos hidrológicos, a dizer que a área do Polígono das Secas era de $320 \mathrm{mil}$ $\mathrm{km}^{2}$ e não de $998 \mathrm{mil} \mathrm{km}^{2}$, como alega a SUDENE e que os índices pluviométricos são 7 vezes maiores que os de Israel. Provavelmente, a
USP não verificou se aquele potencial é potável ou não, porque se sabe que só cerca de $25 \%$ da água do subsolo, na região, serve para o consumo humano ${ }^{14}$.

Independentemente desta análise, a seca continuou durante o ano de 1994, quando 500 agricultores invadiram a SUDENE pedindo providências contra a seca. O Ministério da Agricultura prometia distribuir $150 t$ de alimentos para as cidades afetadas.

Em 1997/99, todo cenário se repete. Veio o El Niño, ocorreu a seca em todo o semi-árido, os camponeses saquearam vilas e cidades e até o Movimento dos Sem-terra (MST) entrou na campanha junto aos camponeses nordestinos. Todavia, uma pergunta paira no ar: que se fez para evitar a repetição destas cenas? Em termos de desenvolvimento, nada. No entanto, se não se substitui a consciência de mitigar o flagelo da seca pela de desenvolver o semi-árido, a região da caatinga indígena, nada vai reduzir as ameaças do próximo El Niño.

\section{Aspectos históricos da mitigação de secas no Nordeste do Brasil}

A história mostra os erros na política de mitigação das secas, que tem sido posta em prática desde o Império (1822-1889) através de táticas paliativas, esclerosadas, tais como, por exemplo, distribuir plantas, mais para incentivar a arborização do que para a agricultura (com a criação do Jardim Botânico, em Olinda), nas primeiras décadas do Século XIX ${ }^{15}$. Com a seca de 1846, começou a distribuição de gêneros alimentícios e formação de frentes de trabalho. Esta última tática se generalizou principalmente a partir da grande seca de 1877 a 1879 . A compra de gêneros, por parte do governo central, terminava por enriquecer a burguesia comercial ${ }^{16}$.

\section{Camelos para o Nordeste}

Em 1859, embora não se vivesse clima de secas, o Estado Imperial

\footnotetext{
$\ldots \ldots \ldots \ldots$

- 13 Idem, ibidem.

- ${ }^{14}$ Idem, ibidem.

-

- ${ }^{15}$ Esta é uma versão do paper de igual título apresentado no Workshop do Simpósio Internacional sobre Meio Ambiente, Degradação e Gerenciamento de Desastres, pelo convênio UFPB-University of Manitoba, Canadá, em Campina Grande, 2 a 7/12/1995.

- ${ }^{16}$ PINTO, (1977: 175/6).
} 
lança mão de uma exótica tentativa de mitigação dos problemas da seca: importa 14 camelos, sendo 10 fêmeas, da Argélia e os envia para o Ceará. Um ano depois, três haviam sido mortos, picados por cobra, ou no processo de parto, e outros tiveram a perna quebrada; nasceram cinco crias. Segundo o Presidente do Ceará, eles se adaptaram muito bem e "devoram com espantosa avidez todos os vegetais do país qualquer que seja seu estado". No entanto, em abril de 1861, só havia 5 animais adultos vivos e duas crias; o restante havia morrido de lepra.

\section{Projetos esquecidos}

Nenhuma tentativa foi feita com reforma agrária. Desde tempos coloniais, os brancos usaram, inclusive, o argumento das secas, para aumentarem suas terras, através de pedidos à Coroa Portuguesa, pelo que chamavam de terras "desabitadas”. O Imperador Pedro II criou a lei de terras (1850), cujo objetivo era a venda das terras disponíveis, inclusive as dos índios. Durante o Império, o Imperador acabou com todas as aldeias indígenas (1862). Inadvertidamente, houve tentativas de colonização de terras com europeus e não com os índios ou seus descendentes, os caboclos.

Tem-se esquecido também de um engenheiro negro, André Rebouças, que defendia uma colonização de terras do governo, pelos próprios nordestinos, o que ele mesmo denominava de Democracia Rural. $\mathrm{Na}$ campanha abolicionista (1870-
1888), os senadores Dantas e Nabuco defendiam um plano de doação de terras aos ex-escravos, junto com a abolição da escravidão. Porém ninguém, num Congresso de latifundiários, se interessou por estas idéias.

Assim, um dos mais graves problemas do Nordeste, a propriedade da terra, que teve início com a tomada das terras indígenas, através da guerra colonialista, permanece intocável até hoje.

\section{A propriedade da água}

O problema maior, no semi-árido brasileiro, não tem sido tanto a terra, senão a água. Embora a construção de açudes tenha sido a política número um, até metade do século $\mathrm{XX}$, não havia sido desenvolvido um sistema adequado de irrigação, permanecendo a grande massa de água sem sua total disponibilidade. Poços e cata-ventos também foram construídos no Ceará desde 1914. Não obstante, o problema continuava, porque se tratava, então, da propriedade da água. Jamais se discutiu sequer o direito das populações campesinas à água. Sequer o Código de Águas, de 1934, mudou esta apropriação individualista e expansivista dos donos de terra (e água). Ser dono de terra significava possuir e controlar todos os mananciais, o que, praticamente, ocorre ainda hoje, embora haja uma nova lei no papel: a Política Nacional de Recursos Hídricos.
Recursos florestais na mitigação da seca

Não obstante, tantos erros também tiveram suas contrapartidas. Para mitigar os efeitos da seca, houve políticas de adequação de reflorestamento. A mais antiga parece ser a introdução da "palmatória" ou simplesmente "palma forrageira" (uma variedade de opuntia, durante a seca de 1877). A tamareira Phoenix dactelifera desde a década de 1910. e várias opuntias, nopaleas, cereus, manilarios e peireskias, e o feijão "tepari”, desde 1917, bem como a algaroba Leguminosa prosopis e a Camaratuba-forrageira, desde 1922 eram usadas nas tentativas de reflorestamento; a faveleira Jatropa hechacantha já era apontada como solução desde 1923, e o mandacaru Cereus jamacaru sem espinhos, desde 1926, como também a palma forrageira Opuntia monocantha sem espinhos, desde 1930.

\section{Considerações gerais}

O discurso das elites por um Nordeste sofrido, "flagelado", tem mascarado a vulnerabilidade mais grave, que é a da propriedade da terra e da água. As comunidades rurais "sertanejas" têm desenvolvido capacidades de resistência e adaptação às secas, na espera de que os efeitos das secas sejam mitigados através de políticas públicas. O Estado, por sua vez, não tem se baseado no grau de risco e vulnerabilidade a que estão submetidas estas comunidades, como parte política do processo de 
Tabela 05

Cronologia de Políticas Públicas

\begin{tabular}{|c|l|l|}
\hline Ano & \multicolumn{1}{|c|}{ Evento/Instituição } & \multicolumn{1}{|c|}{ Governo } \\
\hline 1909 & $\begin{array}{l}\text { Criado o IOCS (Inspetoria Federal de Obras Contra as } \\
\text { Secas) construídos 16 açudes }\end{array}$ & Nilo Peçanha \\
\hline $1918 / 22$ & $\begin{array}{l}\text { Criado o IFOCS (Instituto Federal de Obras Contra as } \\
\text { Secas) }\end{array}$ & Epitácio Pessoa* \\
\hline $1915 / 19$ & Concluídas represas começadas no Século XIX & V. Brás/D. Moreira/E. Pessoa \\
\hline 1920 & Criada a Caixa de Socorro às secas & Epitácio Pessoa \\
\hline 1922 & $60 \%$ da Paraíba é oficializada como área de seca & Epitácio Pessoa \\
\hline $1932 / 35$ & Campos de concentração/frentes de trabalho, açudes & G. Vargas \\
\hline 1936 & Delimitado o Polígono das secas & G. Vargas \\
\hline 1945 & $\begin{array}{l}\text { Criado o DNOCS (Departamento Nacional de Obras } \\
\text { contra a Seca) }\end{array}$ & Vargas/ Dutra \\
\hline 1946 & Delimitado o Polígono das secas & Dutra \\
\hline- & Criação do Banco do Nordeste do Brasil (?) & - \\
\hline 1951 & Redelimitado o Polígono das secas & G. Vargas \\
\hline 1959 & Criada a agência SUDENE & J. Kubitschek \\
\hline 1968 & Construídos, pelo DNOCS, 8.299 poços & Governo Militar \\
\hline 1990 & Fechado o DNOCS & F. Collor \\
\hline
\end{tabular}

$\left.{ }^{\star}{ }^{\star}\right)$ Epitácio Pessoa era paraibano.

desenvolvimento, limitando as ações a mitigar os efeitos da seca, tendo, com isto, lucros políticos, eleitorais, econômicos e sociais. Os anos de seca têm aumentado com os séculos, não porque aumenta o número de secas, de aparecimento do fenômeno, mas pelo grau de povoamento e, portanto, pelas áreas de risco que se ampliam, aumentando com isto a vulnerabilidade.

\section{Bibliografia}

ALMEIDA, José Américo de. $A$ Paraíba e seus Problemas. (3a. edição) João Pessoa, A União, 1980.

ARAGÃO, Oribe. O Que é El Niño? (Conferência). In: SEMINÁRIO SOBRE A INFLUÊNCIA DO EL NIÑO NA AGRICULTURA E

\section{NOS RECURSOS HÍDRICOS} DO SEMI-ÁRIDO. Campina Grande - PB, 12 e 13 de março de 1998.

BRASIL. Ministério do Meio Ambiente dos Recursos Hídricos e da Amazônia Legal. Lei No $9.433 \mathrm{de}$ 8 de janeiro de 1997, que regula a Política Nacional de Recursos Hídricos.

BRITISH PARLIAMENTARY PAPER, LXXV, 1878. Report by Consul Walker on the Famine in the Northern Provinces of Brazil. London, 1878.

CAMPOS DE CONCENTRAÇÃO, a face mais cruel da seca. O Globo, Rio de Janeiro, 22 de março de 1998, p.16.
Convenção das Nações Unidas de Combate à Desertificação. Brasília: Ministério do Meio Ambiente dos Recursos Hídricos e da Amazônia Legal.

CUNHA, Euclides da. Os Sertões. Rio de Janeiro: Francisco Alves, 1981.

Canudos e Outros Temas. Brasília: Senado Federal, 1993, pp. 148-159.

DOMINGOS, Manuel Neto. Seca, Seculorum, Flagelo e Mito na Economia Rural Piauiense. 2a edição, Teresina: CEPRO, 1987.

GIRÃO, Raimundo. Pequena História do Ceará. Fortaleza: Ed. Universidade do Ceará, 1984.

MELO, Antônio Sérgio Tavares. Desertificação, aridez e seca Uma contribuição didática. Texto preparado para a mesa redonda, secas e estratégias no semi-árido, aspectos ecológicos, sociais e degradação ambiental, João Pessoa, (PB) 1996.

MELO, Josemir Camilo de. Aspectos da mitigação de secas no Nordeste de Brasil. (Workshop). In: SIMPÓSIO INTERNACIONAL SOBRE MEIO AMBIENTE, DEGRADAÇÃO E GERENCIAMENTO DE DESASTRES, UFPB/University of Manitoba, Canadá. Campina Grande: 4 de dezembro de 1995.

MOLION, Luiz Carlos Baldicero. Secas, o Eterno Retorno. Ciência Hoje, vol. 3, $\mathrm{N}^{\circ}$ 18, maio/junho, 1985, p. 26-32.

PINTO, Irineu Ferreira. Datase Notas para a História da Paraíba. João 
Pessoa, Editora da UFPB, 1977, (2 vols.).

REBOUÇAS, André. A Seca nas Provincias do Norte. Socorros Públicos. Rio de Janeiro, 1877.

TAKEYA, Denise Monteiro. Um outro Lado do Nordeste: O Algodão na Economia do Rio Grande do Norte (1880-1915). Fortaleza: BNB, 1985.

UNIVERSIDADE FEDERAL DA PARAÍBA. Modelo de Desenvolvimento Integrado para o Semi-Árido. Programa de Estudo e Ações para o Semi-árido. (PEASA) UFPB, 1995.

WILCHES-CHAUX, Gustavo. La Vulnerabilidad Global. In: MASKREY, Andrew (compilador) Los Desastres no son Naturales. La Red de Estudios Sociales en Prevención de Desastres en América Latina, Lima (Peru), pp.1-50. 